\title{
Pengaruh Struktur Material Paduan Berbasis Zirkonium terhadap Ketahanan Korosi dalam Larutan $\mathrm{HNO}_{3}$
}

\author{
Triwikantoro, ${ }^{*}$ Yusri Nur Rozaqi, dan Setyawan Wijayanto \\ Jurusan Fisika FMIPA ITS Surabaya 60111
}

\begin{abstract}
Intisari
Telah dilakukan penelitian pengaruh struktur material paduan berbasis Zirkonium terhadap ketahanan korosi dalam larutan $\mathrm{HNO}_{3}$. Paduan berbasis Zirkonium dengan struktur bervariasi disintesis menggunakan metode pendinginan cepat (paduan amorf) dan pemanasan antara $\mathrm{T}_{g}-\mathrm{T}_{x}$ (paduan nanokristal). Setelah pemanasan tersebut sampel, ukuran kristal yang terbentuk berkisar antara 4 - $20 \mathrm{~nm}$.Paduan dengan struktur tertentu diuji ketahanan korosinya mengunakan larutan $\mathrm{HNO}_{3}$ dengan variasi konsentrasi 0,1 dan 0,01 Molar. Laju korosi ditentukan dengan menggunakan metode pengurangan berat, kemudian struktur mikro setelah uji korosi diamati menggunakan mikroskop optik dan difraksi sinar x. Berdasar data laju korosi, korosi yang terjadi untuk material amorf lebih kecil dibanding dengan nanokristal pada konsentrasi larutan $\mathrm{HNO}_{3} 0,1 \mathrm{M}$ dan $0,01 \mathrm{M}$ untuk paduan $\mathrm{Zr}-\mathrm{Ni}$ dan $\mathrm{Zr}-\mathrm{Cu}-\mathrm{Ni}-\mathrm{Al}$. Berdasar gambar strukturmikro menggunakan mikroskop logam teramati jenis lokal korosi. Hasil data difraksi $X$-ray menunjukkan bahwa sisa fasa yang terbentuk setelah korosi adalah $\mathrm{ZrO}_{2}$, $\mathrm{Zr}_{2} \mathrm{Ni}$ dan $\mathrm{Al}_{2} \mathrm{O}_{3}$.
\end{abstract}

KATA KUNCI: amorf, nanomaterial, Zirkonium, korosi

\section{PENDAHULUAN}

Perkembangan ilmu pengetahuan dan teknologi di bidang material menuntut tersedianya meterial dengan kinerja yang tinggi. Rekayasa material menjadi sebuah kebutuhan, mengingat keterbatasan material murni, baik dari segi jumlah ataupun sifat yang diinginkan sehubungan dengan penerapannya. Penelitian untuk mendapatkan bahan baru dengan kinerja tinggi banyak dilakukan orang, khususnya di negara-negara Industri seperti Amerika, Eropa dan Jepang. Salah satu bahan baru yang saat ini dikembangkan adalah bahan logam dengan struktur amorf, yang sering disebut gelas metalik ( metallic glasses). Secara termodinamik bahan gelas metalik berada pada keadaan metastabil, artinya struktur ini akan mudah bertransformasi menuju ke keadaan yang lebih stabil melalui kristalisasi baik penuh (kristalisasi sempurna) maupun sebagian (kristalisasi sebagian). Pada struktur gelas atom-atom tersusun secara periodik, tetapi tidak berjangkauan panjang. Struktur gelas metalik pertama kali ditemukan oleh P. Duwez untuk paduan Au-Si pada tahun 1960 [1].

Penelitian bidang Nanoteknologi dewasa ini mendapat perhatian dunia, baik penelitian dasar maupun aplikasi. Di negara - negara industri seperti Jepang, USA dan negara - negara di Eropa, nanomaterial diproduksi skala besar menggunakan hasil rekayasa nanoteknologi [2]. Reduksi ukuran material ke dalam skala nanometer dilakukan dengan mempertimbangkan sifat material yang unggul, mencakup sifat fisika, kimia, mekanik, listrik. Material nanokristal memiliki keunggulan dibandingkan dengan maetrial mikrokristal. Hasil penelitian menunjukkan bahwa material dengan struktur nanokristal berbasis Zirkonium mempunyai ketahanan ok-

${ }^{*}$ E-MAIL: triwi@physics.its.ac.id sidasi yang lebih tinggi dibandingkan dengan material amorf atau material berstruktur quasikristal [3].

Zirkonium sebagai elemen pemadu digunakan sebagai penguat dalam pembuatan baja, porselin, paduan nonferrous tertentu dan juga sebagai refraktor. Selain itu Zirkonium digunakan juga dalam tabung vakum untuk menjejak gas - gas karena mudah berikatan dengan oksigen, hidrogen dan nitrogen pada temperatur tinggi. Pemanfaatan lainnyapada alat penukar kalor, pompa, katup dan peralatan lain yang tahan korosi di lingkungan asam. Paduan khusus Zirkonium Zircalloy2 dan Zircalloy-4 digunakan sebagai material cladding untuk elemen bakar nuklir, karena tampang lintang serapan terhadap neutron rendah, tahan terhadap korosi pada temperatur tinggi, ulet dan mudah difabrikasi [4].

Pada makalah ini disajikan hasil penelitian pengaruh struktur (amorf dan kristal (nanokristal)) terhadap perilaku korosi dalam larutan 0,$1 ; 0,01 \mathrm{M} \mathrm{HNO}_{3}$ untuk paduan berbasis $\mathrm{Zr}$. Pengetahuan pengaruh struktur terhadap perilaku korosi ini bermanfaat dalam memperbaiki kinerja material khususnya terkait dengan sifat elektrokimianya.

\section{DASAR TEORI}

Korosi merupakan suatu bentuk degradasi kualitas material akibat adanya reaksi kimia dengan lingkungan. Perbaikan kinerja material terkait dengan sifat - sifatnya dapat dilakukan melalui beberapa cara: memberikan perlakuan panas untuk merubah struktur mikro, memvariasi komposisi dengan mengubah konsentrasi atau menambahkan elemen pemadu [5]. Struktur mikro memegang peran yang cukup signifikan dalam menentukan sifat material. Material paduan amorf memiliki keuletan tinggi dengan struktur mikro sangat sedikit batas butir, sedangkan struktur material kristal umumnya lebih keras dengan relatif banyak batas butir dibanding material amorf. 
Korosi merupakan reaksi kimia yang tergolong ke dalam oksidasi. Secara umum dapat dituliskan [6]:

\begin{tabular}{|c|c|c|}
\hline $\begin{array}{r}\mathrm{M} \\
\mathrm{O}+2 \mathrm{e}^{-} \rightarrow\end{array}$ & $\begin{array}{c}\mathrm{M}^{n+}+\mathrm{ne}^{-} \\
\mathrm{O}^{2-}\end{array}$ & $\begin{array}{l}\text { Anoda } \\
\text { Katoda }\end{array}$ \\
\hline $\mathrm{M}+\mathrm{O} \rightarrow$ & MO & (tergantung elektron valensi \\
\hline
\end{tabular}

Mekanisme pembentukan produk korosi atau oksidasi berdasar tinjauan elektrokimia bisa dituliskan:

- tahap dissosiasi oksigen $\mathrm{O} \rightarrow \mathrm{O}^{-} \rightarrow \mathrm{O}^{2-}$ siap untuk physicsorption pada permukaan metal

- tahap ionisasi ion Metal $\rightarrow \mathrm{Mn}^{+}+\mathrm{ne}^{-}$

- Difusi ion metal dan ion $\mathrm{O}^{2-}$ ke permukaan dan terjadi chemisorption membentuk lapisan kompak di permukaan aatau lapisan mudah mengelupas.

Laju korosi bisa dihitung berdasar pengurangan atau penambahan massa dari material awal terhadap produk korosi. Secara umum laju ini bisa dituliskan:

$$
y=k t^{n}
$$

dengan $\mathrm{y}=$ massa per satuan luas, $\mathrm{t}=$ waktu reaksi, $\mathrm{n}=$ orde reaksi

Proses perlakuan panas adalah suatu proses pemanasan atau pendinginan yang bertujuan merubah struktur mikro paduan. Proses ini selain bergantung pada temperaatur, juga waktu pemanasan. Pemanasan menjadikan paduan lebih homogen, tegangan sisa berkurang, kekuatan meningkat. Berubahnya struktur akibat pemanasan dapat terjadi melalui transformasi fasa. Fasa baru terbentuk dengan tahapan proses pengintian dan pertumbuhan. Ada 2 jenis pengintian, yaitu pengintian homgen (jika inti kristal terbentuk dari fasa cairnya) dan heterogen (jika inti terbentuk dengan hadirnya permukaan luar atau fasa sekunder). Pertumbuhan inti kristal terjadi, jika jarijari inti yang terbentuk lebih besar dari jari-jari inti kritis[7].

Transformasi bisa dimungkinakan dari fasa awal amorf yang dipanaskan berubah menjadi kristal (kristalisasi fasa amorf). Perubahan dari fasa amorf menjadi kristal ini dapat terjadi dalam berbagai cara. Gambar 1. menjelaskan tentang kristalisasi ini. Berdasarkan Gambar 1, ada beberapa transformasi yang bisa terjadi dari keadaan awal amorf. Secara umum ada tiga macam kristalisasi dari fasa amorf ke fasa kristal, yaitu[8]:

1. Kristalisasi Polimorfi, yaitu pembentukan kristal dari fasa amorf dengan komposisi kimia yang sama. Seperti ditunjukkan garis nomor 1 pada Gambar 1 dengan reaksinya : amorf $\rightarrow \alpha$ atau amorf $\rightarrow \beta$

2. Kristalisasi Primer, yaitu pembentukan kristal dari fasa amorf menjadi kristal dengan sisa fasa amorf. Seperti ditunjukkan garis nomor 2 pada Gambar 1 dengan reaksinya : amorf $\rightarrow \alpha+$ amorf atau amorf $\rightarrow \beta+$ amorf

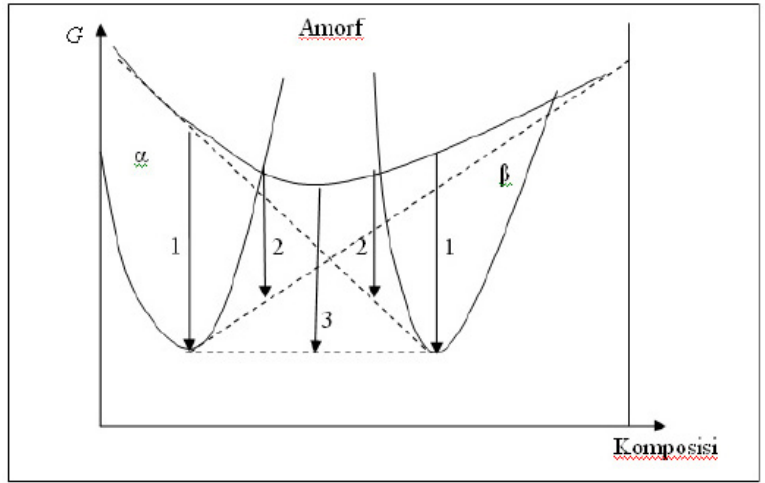

Gambar 1: Diagram hipotektik transformasi fasa dari amorf menuju fasa kristal [8]

3. Kristalisasi Eutektik, yaitu pembentukan kristal dari fasa amorf menjadi kristal dengan komposisi berbeda. Seperti ditunjukkan garis nomor 3 pada Gambar 1 dengan reaksinya : amorf $\rightarrow \alpha+\beta$

\section{METODOLOGI PENELITIAN}

Paduan amorf berbasis $\mathrm{Zr}$ terdiri dari $\mathrm{Zr}_{67} \mathrm{Ni}_{33}$, $\mathrm{Zr}_{69.5} \mathrm{Cu}_{12} \mathrm{Ni}_{11} \mathrm{Al}_{7.5}$ at.\% disediakan untuk diuji korosi. Kedua paduan tersebut dipanaskan pada daerah $\mathrm{T}_{g}-\mathrm{T}_{x}$ untuk mendapatkan struktur (nano)kristal, kemudian diuji korosi. Hasil uji korosi paduan amorf dibanding dengan paduan yang telah dipanaskan untuk mengetahui perilaku korosi dalam 0,1 $\mathrm{M}$ dan 0,01 $\mathrm{M}$ larutan $\mathrm{HNO}_{3}$. Laju korosi diukur dengan metode pengurangan massa (secara diskuntinyu). Fasa sebelum dan sesudah korosi dianalisis menggunakan difraksi sinar $\mathrm{x}$ dengan metode perunutan dan pencocokkan. Ukuran kristal ditentukan menggunakan persamaan Scherrer. Ukuran kristal, uji difraksi dan perhitungan laju korosi dibandingkan antara sampel sebelum dan sesudah dipanaskan.

\section{HASIL DAN PEMBAHASAN}

Sampel paduan amorf berbasis $\mathrm{Zr}$ sebagian dipanaskan pada $380-400^{\circ} \mathrm{C}$ untuk mendapatkan struktur kristal pada daerah $\mathrm{nm}$. Hasil perhitungan menggunakan persamaan scherrer didapatkan ukuran kristal yang terbentuk antara 4 $42 \mathrm{~nm}$ (Tabel 1). Data laju korosi dapat dilihat pada Tabel 2. Berdasar tabel tersebut, terlihat bahwa laju korosi material amorf (sebelum dipanaskan) lebih kecil dibanding dengan sampel yang dipanaskan pada temperatur 380,390 dan $400^{\circ} \mathrm{C}$. Terbentuknya kristal dalam paduan akan mengakibatkan timbulnya batas butir. Mekanisme reaksi oksidasi/korosi pada paduan berbasis $\mathrm{Zr}$ dalam larutan $\mathrm{HNO}_{3}$ ditandai dengan pembentukan oksida $\mathrm{ZrO}_{2}$ atau $\mathrm{Al}_{2} \mathrm{O}_{3}$. Penguraian $\mathrm{HNO}_{3}$ ke dalam bentuk ion menyebabkan ion negatif (O2-) bereaksi dengan ion logam membentuk oksida. Berdasar energi bebas pembentukan $\mathrm{Al}_{2} \mathrm{O}_{3}$ lebih kecil dibanding $\mathrm{ZrO}_{2}$, den- 


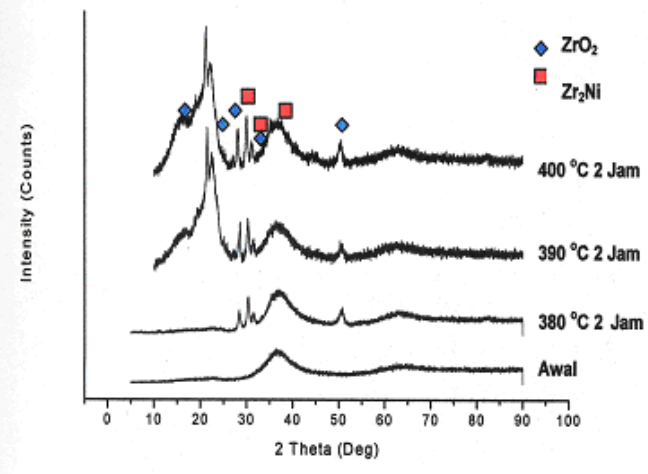

Gambar 2: Pola difraksi sempel ZrNi setelah dipanaskan dan terkorosi dalam $\mathrm{HNO}_{3}$

gan demikian awal akan terbentuk $\mathrm{Al}_{2} \mathrm{O}_{3}$ baru $\mathrm{ZrO}_{2}$. Untuk mengetahui hal ini, dapat diuji menggunakan x-ray terhadap produk korosi atau sisa korosi yang masih menempel pada sampel.

TABEL I: Ukuran kristal sampel yang dipanaskan 380, 390 dan $400^{\circ} \mathrm{C}$

\begin{tabular}{lcc}
\hline \hline Temperatur & $\mathrm{Zr}-\mathrm{Ni}$ & $\mathrm{Zr}-\mathrm{Cu}-\mathrm{Ni}-\mathrm{Al}$ \\
\hline & & - \\
amorf & - & $(4-8 \mathrm{~nm})$ \\
$380^{\circ} \mathrm{C}$ & $\mathrm{ZrO}_{2} \& \mathrm{Zr} 2 \mathrm{Ni}$ & $\mathrm{Zn}$ \\
$390^{\circ} \mathrm{C}$ & $\mathrm{ZrO}_{2} \& \mathrm{Zr} 2 \mathrm{Ni}(6-13 \mathrm{~nm})$ & $\mathrm{Al}_{2} \mathrm{O}_{3} \& \mathrm{Zr} 2 \mathrm{Ni}(4-29 \mathrm{~nm})$ \\
$400^{\circ} \mathrm{C}$ & $\mathrm{ZrO}_{2} \& \mathrm{Zr} 2 \mathrm{Ni}(8-42 \mathrm{~nm})$ & $\mathrm{Al}_{2} \mathrm{O}_{3} \& \mathrm{Zr} 2 \mathrm{Ni}(5-31 \mathrm{~nm})$
\end{tabular}

TABEL II: Data laju korosi sampel paduan berbasis Zr-Ni dan Zr$\mathrm{Cu}-\mathrm{Ni}-\mathrm{Al}$

\begin{tabular}{lcccc}
\hline \hline & $\begin{array}{l}\mathrm{Zr}-\mathrm{Ni} \\
0,01 \mathrm{M} \mathrm{HNO}_{3}\end{array}$ & $\begin{array}{c}\mathrm{Zr}-\mathrm{Cu}-\mathrm{Ni}-\mathrm{Al} \\
0,01 \mathrm{M} \mathrm{HNO}_{3}\end{array}$ & $\begin{array}{c}\mathrm{Zr}-\mathrm{Ni} \\
0,1\end{array} \mathrm{M} \mathrm{HNO}_{3}$ & $\begin{array}{c}\mathrm{Zr}-\mathrm{Cu}-\mathrm{Ni}-\mathrm{Al} \\
0,1 \mathrm{M} \mathrm{HNO}{ }_{3} \mathrm{~T}\end{array}$ \\
\hline \multirow{3}{*}{ Amorf } & 34,33 & 49,79 & 24,89 & 37,34 \\
$380^{\circ} \mathrm{C}$ & 39,70 & 50,30 & 39,30 & 49,20 \\
$390^{\circ} \mathrm{C}$ & 53,00 & 74,20 & 46,70 & 66,40 \\
$400^{\circ} \mathrm{C}$ & 66,30 & 76,90 & 59,10 & 68,90 \\
& & & & \\
\hline \hline
\end{tabular}

Hasil uji difraksi sinar-X untuk material sesudah korosi dapat dilihat pada gambar 2. Hasil identifikasi fasa menggunakan metode "search and match" fasa - fasa yang telah diidentifikasi adalah $\mathrm{ZrO}_{2}$ dan $\mathrm{Al}_{2} \mathrm{O}_{3}$ untuk paduan amorf $\mathrm{Zr}$, sedangkan $\mathrm{Zr} 2 \mathrm{Ni}$ dan $\mathrm{ZrO}_{2}$ terdapat pada sampel terkorosi setelah pemanasan (sampel nanokristal). Dari kedua paduan jika pola difraksi dibandingkan setelah uji korosi terlihat bahwa puncak - puncak difraksi yang terbentuk mulai $380^{\circ} \mathrm{C}$ pada $\mathrm{Zr}-\mathrm{Ni}$ dan mulai $390^{\circ} \mathrm{C}$ pada $\mathrm{Zr}-\mathrm{Cu}-\mathrm{Ni}-\mathrm{Al}$. Dari hasil ini dapat dikatakan bahwa penambahan $\mathrm{Al}$ dan $\mathrm{Cu}$ meningkatkan nilai ketahanan korosi [9].

Permukaan sampel terkorosi diamati menggunakan mikroskop optik untuk mengetahui jenis korosi yang ada. Berdasar gambar mikro ini, tidak ada perbendaan yang mencolok antara paduan amorf dan nanokristal berbasis $\mathrm{Zr}$. Umumnya permukaan terkorosi adalah korosi lokal. Hal ini bisa dimungkinkan oleh adanya ketidakhomogenan sampel atau kondisi permukaan yang tidak benar-benar merata.

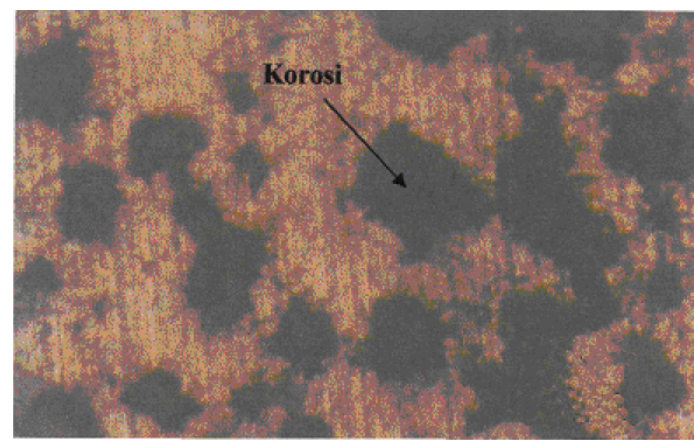

Gambar 3: Struktur mikro sampel terkorosi 0,1 $\mathrm{M} \mathrm{HNO}_{3}$

\section{SIMPULAN}

Berdasar data hasil perhitungan laju korosi, pengamatan difraksi sinar $\mathrm{x}$ dan mikrografi dapat diambil beberapa kesimpulan.

1. Laju korosi paduan amorf berbasis Zirkonium lebih rendah dibanding paduan nanokristal, ini berarti struktur kristal dengan hadirnya batas butir mengakibatkan korosi terkonsentrasi didalamnya.

2. Produk korosi teridentifikasi $\mathrm{ZrO}_{2}$ dan $\mathrm{Al}_{2} \mathrm{O}_{3}$, fasa intermetalik yang timbul dikarenakan kristalisasi fasa amorfnya.

3. Laju korosi paduan biner Zr-Ni lebih tinggi dibanding dengan $\mathrm{Zr}-\mathrm{Cu}-\mathrm{Ni}-\mathrm{Al}$, ini berarti bahwa penambahan elemen $\mathrm{Cu}$ dan $\mathrm{Al}$ menambah ketahanan korosi dalam larutan $0,1 \mathrm{M}$ dan $0,01 \mathrm{M} \mathrm{HNO}_{3}$.
[1] Klement W., Willens RH., Duwez P, Nature 187, 869 (1960)

[2] Inoue A, Forntier in Bulk metallic Glssy and nanostructured alloys challenges as we approach 2010, http://www.liquidmetalgolf.com/advboard (2003)
[3] Triwikantoro, Studi pengaruh struktur mikro pada sifat oksidasi dan kristalisasi bahan gelas metalik berbasis zirkonium, Proc. Seminar nasional Lemlit ITS Surabaya (2002)

[4] Microsoft Encarta reference Library (2005) 
[5] Flemming M.C., Cahn R.W., Acta Mater., 48,371 - 383.

[6] Petter W.H. et.al., Journal scripta matter, no.10, 1157 - 1162 (2002)

[7] Rao C.N.R, Rao K.J., Phase Transition in Solid, pp. 92

[8] Koester U.(1993), Phase transformation in Rapidly solidification alloys, Key Engineering Materilas, vol. 81 - 83 pp. 647 - 662
(1978)

[9] Setyawan W., Perilaku korosi pada material nanokristal dari bahan dasar amorf berbasis $\mathrm{Zr}$ dalam lingkungan $\mathrm{HNO}_{3}$, Tugas akhir jurusan Fisika FMIPA-ITS (2006). 